\title{
Hydrothermal synthesis of $\mathrm{NiFe}_{2} \mathrm{O}_{4}$ nano-particles: structural, morphological, optical, electrical and magnetic properties
}

\author{
K CHANDRA BABU NAIDU and W MADHURI* \\ Ceramic Composites Laboratory, Centre for Crystal Growth, VIT University, Vellore 632014, India
}

MS received 20 April 2016; accepted 2 July 2016

\begin{abstract}
NiFe}_{2} \mathrm{O}_{4}$ nano-crystallites with an average diameter of $8.9 \mathrm{~nm}$ are synthesized via hydrothermal method. The single-phase spinel structure is confirmed from X-ray diffractograms. Morphology is analysed by transmission and field emission scanning electron microscopes. High specific surface area of $55.7 \mathrm{~m}^{2} \mathrm{~g}^{-1}$ is obtained for nano-particles. The $M-H$ loop and $M-T$ curve behaviours are investigated by vibrating sample magnetometry. The optical band gap energy is estimated from the UV-visible spectrum. In addition, the frequency dependence of dielectric properties is investigated. Cole-Cole plots are drawn to study electrical conduction mechanism and the kind of relaxation-Debye or non-Debye type. Low a.c. conductivity and low magnetic losses are noticed at $5 \mathrm{MHz}$ frequency, which are suitable for microwave device applications.
\end{abstract}

Keywords. Nano-materials; transmission electron microscope; dielectric constant; permeability; magnetic properties.

\section{Introduction}

Nano-ferrites are promising materials for microwave devices, magnetic resonance imaging (MRI), catalysis, magnetic recording, microwave absorbers, biosensors, biomedical drug delivery, power transformers and telecommunication applications, due to their high thermal stability and enhanced electrical, optical and magnetic properties when compared with bulk materials [1-4]. Nano-nickel-ferrite is a mixed spinel ferrite having cation distribution of $\left[\mathrm{Ni}^{2+} \mathrm{Fe}^{3+}\right]_{\mathrm{A}}\left[\mathrm{Ni}^{2+} \mathrm{Fe}^{3+}\right]_{\mathrm{B}}$ [5]. Many researchers have successfully synthesized $\mathrm{NiFe}_{2} \mathrm{O}_{4}$ nano-particles by various techniques such as co-precipitation [6], green nano-technology [7], sol-gel [8], reactive milling [9], solvothermal [10] and egg-white precursor [11] methods in order to investigate the structural, optical, morphological, electrical and magnetic properties. However, the hydrothermal method offers many advantages over the other methods such as low cost for sample preparation, high crystallinity, simplicity and usage of low temperatures. In this investigation, additionally, dielectric properties, impedance spectroscopic analysis and magnetic permeability properties are explored for as-synthesized nano-particles, which have not been reported earlier by the hydrothermal technique.

\section{Experimental}

In order to synthesize $\mathrm{NiFe}_{2} \mathrm{O}_{4}$ nano-particles, $\mathrm{Ni}\left(\mathrm{NO}_{3}\right)_{2}$. $6 \mathrm{H}_{2} \mathrm{O}, \mathrm{Fe}\left(\mathrm{NO}_{3}\right)_{3} \cdot 9 \mathrm{H}_{2} \mathrm{O}$ (each of $99.8 \%$ purity, Sigma Aldrich) and $\mathrm{NaOH}$ are taken as precursors. Deionized water

*Author for correspondence (madhuriw12@gmail.com) is used as a solvent. Nickel and iron nitrates are dissolved in distilled water by maintaining the ratio of nitrates $(\mathrm{g})$ :water $(\mathrm{ml})$ as 1:3. The resultant solution is stirred until it gets converted into nano-particles. $\mathrm{NaOH}(\mathrm{g})$ is added little by little to the solution $(\mathrm{ml})$ in $1: 4(\mathrm{NaOH}$ :nitrates) ratio. The $\mathrm{pH}$ of 11 is maintained in the mixture to achieve pure spinel phases. Furthermore, the mixture is vigorously stirred for $2 \mathrm{~h}$ and transferred into a $300 \mathrm{ml}$ Teflon-lined steel autoclave. The sealed autoclave is heat treated at $150^{\circ} \mathrm{C}$ for $48 \mathrm{~h}$. After $48 \mathrm{~h}$ the autoclave is slowly cooled to room temperature (RT). The precursor in the autoclave is filtered and washed with acetone and distilled water many times till $\mathrm{pH}$ is decreased to 7. Later, nickel ferrite (NF) nano-particles are separated from the autoclave and dried at $60^{\circ} \mathrm{C}$ for $6 \mathrm{~h}$. The synthesis part is depicted in figure 1 . The as-prepared powder is characterized using an X-ray diffractometer (Bruker $\mathrm{X}$-Ray Powder Diffraction Meter, $\mathrm{Cu}_{\mathrm{K} \alpha}, \lambda=0.15418 \mathrm{~nm}$ ), a Field-emission Scanning Electron Microscope (Ultra 55 FE-SEM Carl Zeiss), a Transmission Electron Microscopy (TEM: Model Tecnai G20, FEI, USA), a JASCO UV-visible spectrophotometer (V-670 PC), an FT-IR spectrophotometer (IR affinity-1, Shimadzu), a HIOKI 3532-50 LCR controller (Japan) and a Vibrating Sample Magnetometer (EV-7 VSM with maximum applied field of $+15 \mathrm{kOe}$ ) for structural, morpho logical, optical, electrical and magnetic properties, respectively.

\section{Results and discussion}

\subsection{Structural analysis}

Figure $2 \mathrm{a}$ depicts the variation of intensity as a function of two-theta angle $(2 \theta)$ from $10^{\circ}$ to $80^{\circ}$ for $\mathrm{NiFe}_{2} \mathrm{O}_{4}$ 


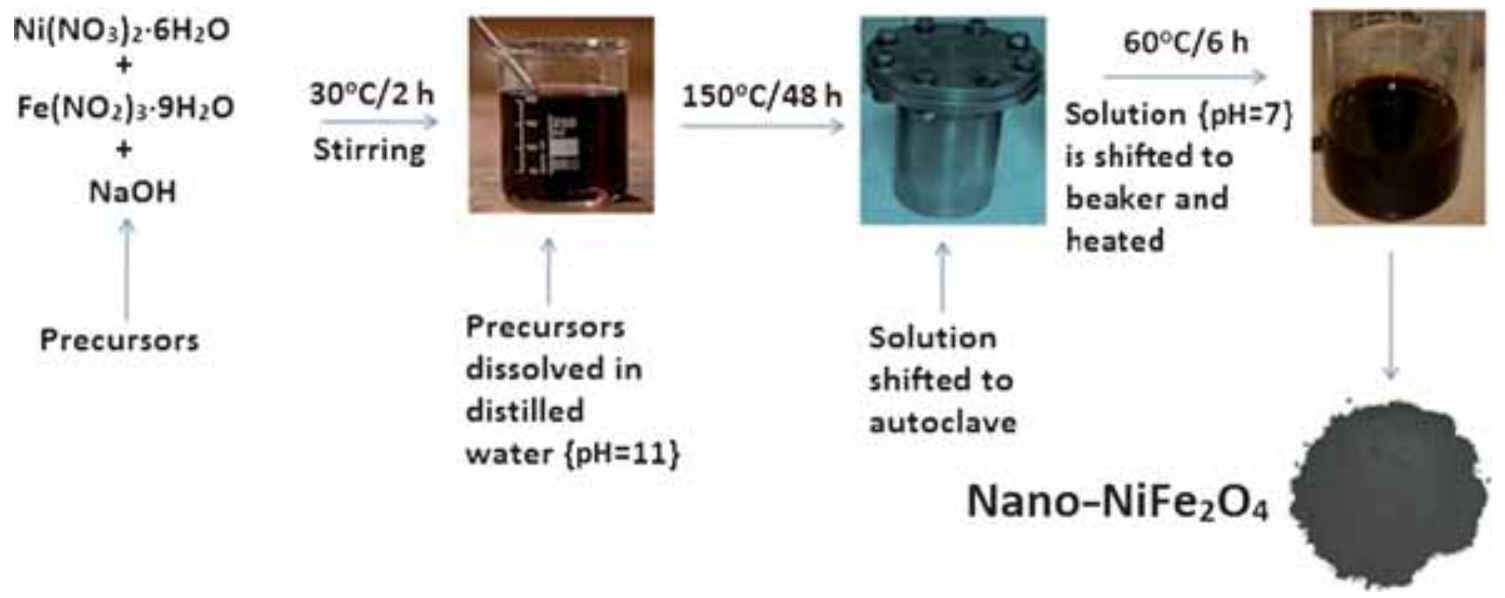

Figure 1. Schematic diagram of synthesis part of nano- $\mathrm{NiFe}_{2} \mathrm{O}_{4}$.
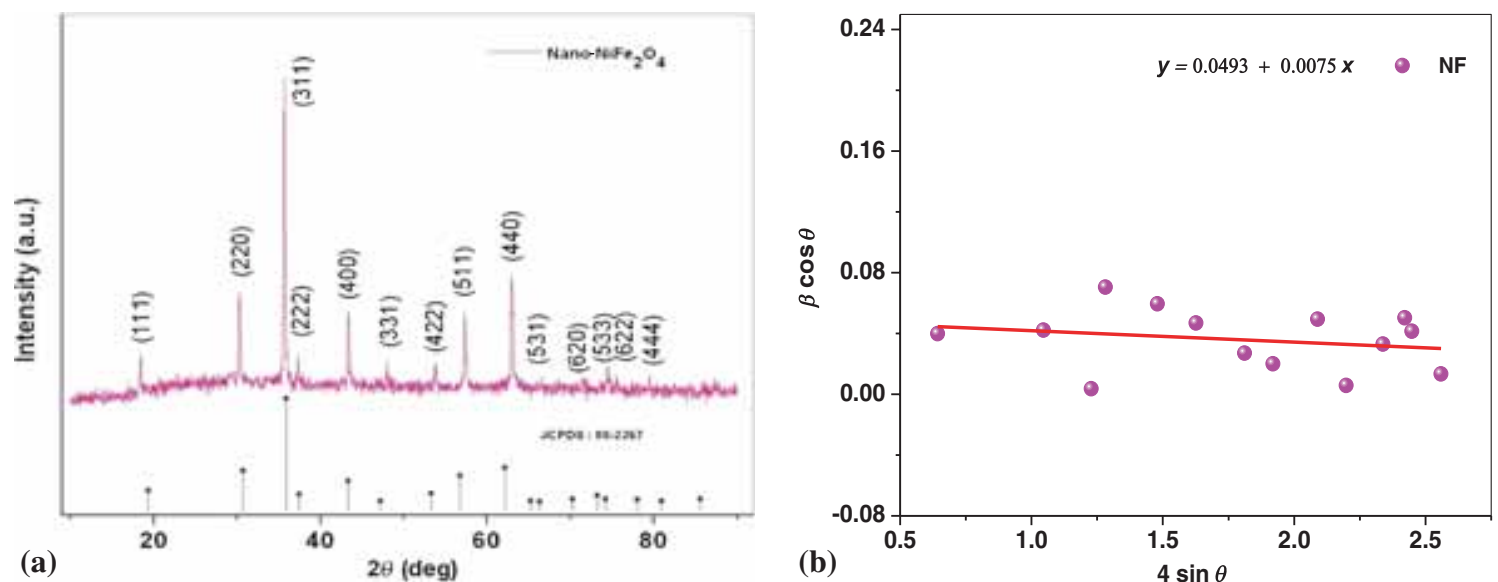

Figure 2. (a) XRD pattern and (b) $\mathrm{W}-\mathrm{H}$ plot of $\mathrm{NiFe}_{2} \mathrm{O}_{4}$ nano-particles.

nano-particles. The diffractogram pattern of as-prepared sample exhibited single-phase formation of face-centred cubic structure with high crystallinity. The locations of Bragg lines with reflections from the planes of (111), (220), (311), (222), (400), (422), (511), (440), (620), (533), (622) and (444) are in good agreement with standard JCPDS: 86-2267. The locations of main peaks are used to find inter-planar spacing $(d)$ of Bragg's lines. No secondary phases are noticed in X-ray analysis. Thus, the obtained NF nano-particles are highly pure in phase. The average crystallite size ' $D$ ' (8.9 $\mathrm{nm}$ ) is determined from average full-width at half-maxima (FWHM) of all reflection peaks using the Debye-Scherrer formula [12]:

$$
D=\frac{0.9 \lambda}{\beta \cos \theta},
$$

where $\beta$ is FWHM, $\lambda$ is wavelength of $\mathrm{Cu}_{\mathrm{K} \alpha}$ source ( 0.1542 $\mathrm{nm})$ and $\theta$ is diffraction angle. The Williamson-Hall (W-H) plot (as shown in figure 2b) is drawn for $\beta \cos \theta$ vs. $4 \sin \theta$ in order to evaluate micro-strain $(\varepsilon)$ and crystallite size $(D)$ using the following relation [13]:

$$
\beta \cos \theta=\frac{0.9 \lambda}{D}+4 \varepsilon \sin \theta,
$$

where slope of the straight line offers micro-strain while crystallite size is associated with the intercept parameter. This gives the correlation between ' $\varepsilon$ ' and ' $D$ ' values. The results are presented in table 1 . The lattice constants $(a, b$ and $c$ ) are computed from inter-planar spacing and Miller indices $(h, k$ and $l)$. The achieved value of ' $a$ ' $(0.833 \mathrm{~nm})$ is almost equal to the reported data [13]. X-ray density (5.393 g $\mathrm{cm}^{-3}$ ) of nano-particles is calculated from the relation $D_{\mathrm{x}}=$ $\mathrm{ZM} / \mathrm{Na}^{3}$, where ' $\mathrm{Z}$ ' is the number of molecules per unit cell $(Z=8)$, ' $M$ ' is the molecular weight of the composition, ' $N$ ' is Avogadro's number $\left(6.023 \times 10^{23}\right)$ and ' $a$ ' is the lattice parameter. Moreover, some structural parameters such as Scherrer strain $\left(\varepsilon^{*}\right)$ and dislocation density $\left(\rho_{\mathrm{d}}\right)$ are calculated using the following relations [14] and are presented in table 1 :

$$
\begin{aligned}
& \varepsilon^{*}=\frac{\beta}{4 \tan \theta}, \\
& \rho_{\mathrm{d}}=\frac{1}{D^{2}} .
\end{aligned}
$$

\subsection{Surface morphology}

Figure 3a shows the TEM images of NF nano-particles. The average particle size $\left(D^{\prime}\right)$ of prepared sample is about $20 \mathrm{~nm}$. 
The obtained NF particle size is much smaller than the value $170 \mathrm{~nm}$ reported by Wang et al [15] via solvothermal technique $\left(180^{\circ} \mathrm{C} / 48 \mathrm{~h}\right)$. The reduction of particle size is attributed to lowering of the annealing temperature in the hydrothermal method $\left(150^{\circ} \mathrm{C} / 48 \mathrm{~h}\right)$. The surface area $(S)$ is a physical property of nano-materials. This gets more importance than its bulk counterpart due to nano-ordered grain size. Basically, nano-materials will have large ' $S$ ' value, whereas bulk materials will have small value. Magnetic properties of ferrites are very sensitive to the surface area [16]. The surface area obtained for the present nano-ferrite, $55.7 \mathrm{~m}^{2} \mathrm{~g}^{-1}$, is very large as calculated from TEM studies using the following relation:

$$
S=\frac{6}{D^{\prime} \rho_{\mathrm{x}}} .
$$

The magnetic interaction between nano-particles is responsible for the weak agglomeration in TEM photographs [16]. The selected area electron diffraction (SAED) indicates the good crystalline nature of single-phase nano- $\mathrm{NiFe}_{2} \mathrm{O}_{4}$ (figure 3b). The SAED pattern is indexed by (311), (400), (511) and (440) planes and is in agreement with diffraction data. The FE-SEM photographs and EDS spectra, including compositional data of as-synthesized $\mathrm{NiFe}_{2} \mathrm{O}_{4}$ powder

Table 1. Data on structural parameters of nano- $\mathrm{NiFe}_{2} \mathrm{O}_{4}$.

\begin{tabular}{lccc}
\hline Parameters & Values & Literature & Reference \\
\hline$D^{\prime}(\mathrm{nm})$ & 20 & 46.2 & 2 \\
$a(\AA)$ & 8.327 & 8.332 & 2 \\
$\rho_{\mathrm{d}} \times 10^{14}\left(\mathrm{~m}^{-2}\right)$ & 126.2 & - & - \\
$\mathrm{FWHM}\left(\beta_{\mathrm{avg}}\right)$ & 0.023 & - & - \\
$D_{\mathrm{x}}\left(\mathrm{g} \mathrm{cm}^{-3}\right)$ & 5.392 & - & - \\
$V$ & 577.4 & - & - \\
$D(\mathrm{~nm})$ from $\mathrm{W}-\mathrm{H}$ plot & 3.2 & - & - \\
Scherrer strain $\varepsilon^{*}$ & 0.0156 & - & - \\
Strain $\varepsilon$ from W-H plot & 0.0075 & - & - \\
$S \times 10^{3}\left(\mathrm{~m}^{2} \mathrm{~g}-1\right)$ from TEM & 55.67 & - & - \\
Optical band gap, $E_{\mathrm{g}}(\mathrm{eV})$ & 1.57 & 1.55 & 2 \\
\hline
\end{tabular}

samples, are shown in figure 4. Diamond-cube-like grains are identified. Average grain size $\left(G_{\mathrm{a}}\right)$ is found to be of order $57.9 \mathrm{~nm}$ using the linear intercept method and is given by

$$
G=\frac{1.5 L}{M N}
$$

where $L$ is the total test line length, $M$ is the magnification and $N$ is the total number of intercepts that the grain boundary makes with the line. EDS attributes the inhibited elements and impurities in the samples with their at $\%$ and $\mathrm{wt} \%$. No impurities are noticed in the EDS spectrum, once again confirming that the synthesized NF nano-particles are pure in nature.

\subsection{UV-visible spectra}

The diffuse reflectance spectrum is recorded in the range of 200-1500 nm for evaluating optical band gap of powder samples. The Kubelka-Munk function of reflectance $F(r)$ is used to determine band gap [17]:

$$
F(r)=\frac{(1-r)^{2}}{2 r} .
$$

The absorption coefficient $(\alpha)$ is directly proportional to $F(r)$ and hence an equation to find band gap can be written as follows:

$$
(\alpha h v)^{n}=m\left(h v-E_{\mathrm{g}}\right)
$$

where $m$ is an energy-independent constant that depends on transition probability, $E_{\mathrm{g}}$ is optical band gap energy, $n$ depends on the kind of transition, i.e., $n=2$ for direct transition, 2/3 for direct forbidden transition, 1/2 for indirect transition and $1 / 3$ for indirect forbidden transition, and $h v$ is photon energy [18]. In this study, $n$ is taken as 2 for direct transition. $E_{\mathrm{g}}$ value is considered as the extrapolated tangent value towards $X$-axis for $(\alpha h v)^{2} v s$. photon energy $h v(\mathrm{eV})$ plot as $\alpha$ tends to zero (figure 5). The band gaps of bulk (microwave sintered at $1000^{\circ} \mathrm{C}$ ) and nano- $\mathrm{NiFe}_{2} \mathrm{O}_{4}(\mathrm{NF})$
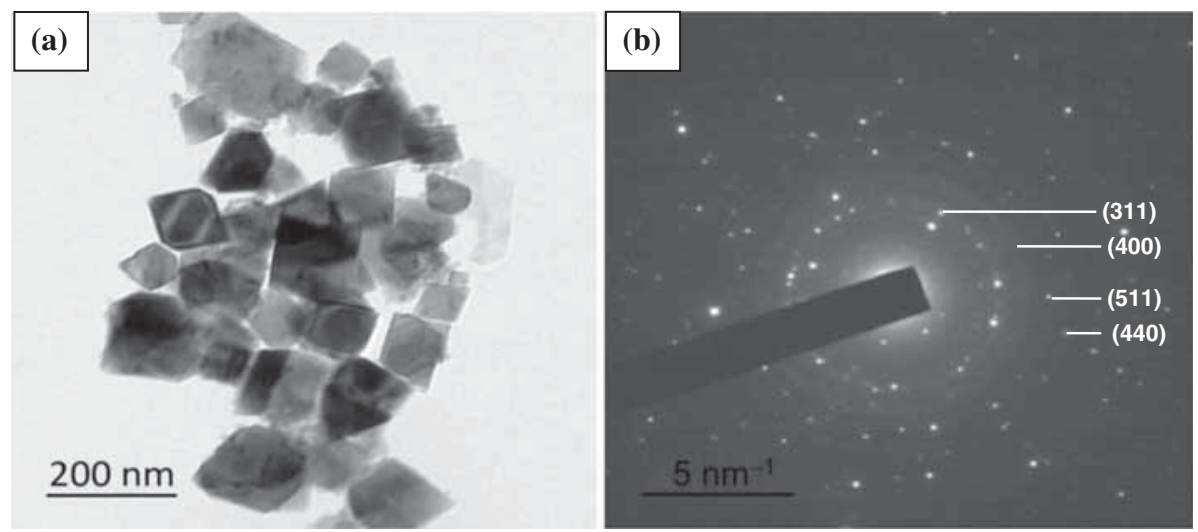

Figure 3. (a) TEM image and (b) SAED pattern of $\mathrm{NiFe}_{2} \mathrm{O}_{4}$ nano-particles. 

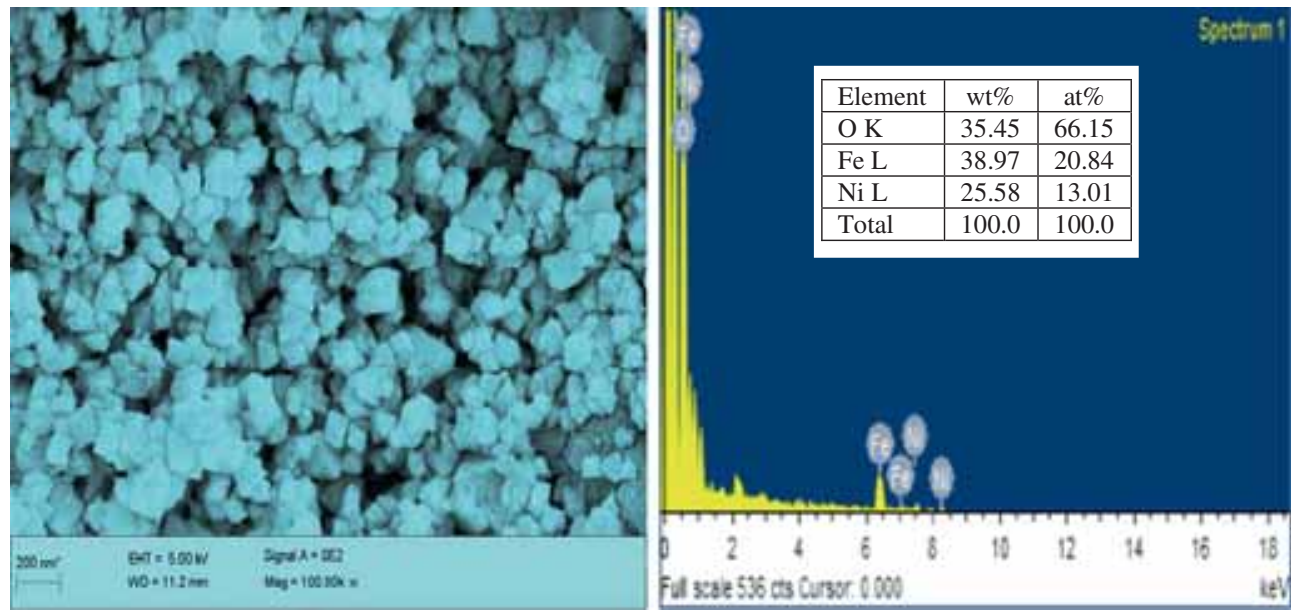

Figure 4. FESEM image and EDS spectra of $\mathrm{NiFe}_{2} \mathrm{O}_{4}$ nano-particles.

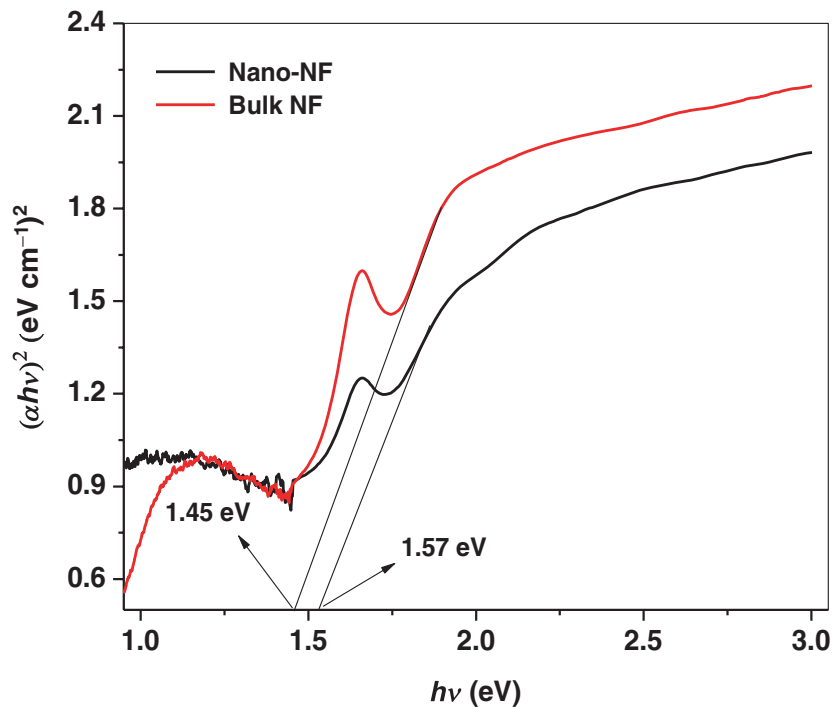

Figure 5. Plot of $(\alpha h v)^{2}$ as a function of $h v$ (photon energy).

samples are calculated to be 1.45 and $1.57 \mathrm{eV}$, respectively. The obtained $E_{\mathrm{g}}$ of nano-NF is in consistent with the reported value of $1.56 \mathrm{eV}$ [19]. Grain size variation and specific surface area are responsible for variation of band gaps of bulk ferrites and nano-ferrites. It is a known fact that the number of oxygen vacancies increases with decrease of grain size [19], i.e., nano-NFs (high surface area) possess more number of oxygen vacancies than their bulk (low surface area). Indeed, these oxygen vacancies act as electron $\left(\mathrm{e}^{-}\right)$trapping centres and play a key role in reducing the recombination rate of photo-induced charge carriers $\left(\mathrm{e}^{-}\right.$and $\mathrm{h}$ ), intensifying photo-catalytic activity of ferrites [20]. However, more number of oxygen vacancies are created in nano- $\mathrm{NiFe}_{2} \mathrm{O}_{4}$, which are able to trap more number of carriers, leading to the reduction of electron-hole $\left(\mathrm{e}^{-}-\mathrm{h}\right)$ separation efficiency. This enhances the photo-catalytic activity of nano-ferrite powders.

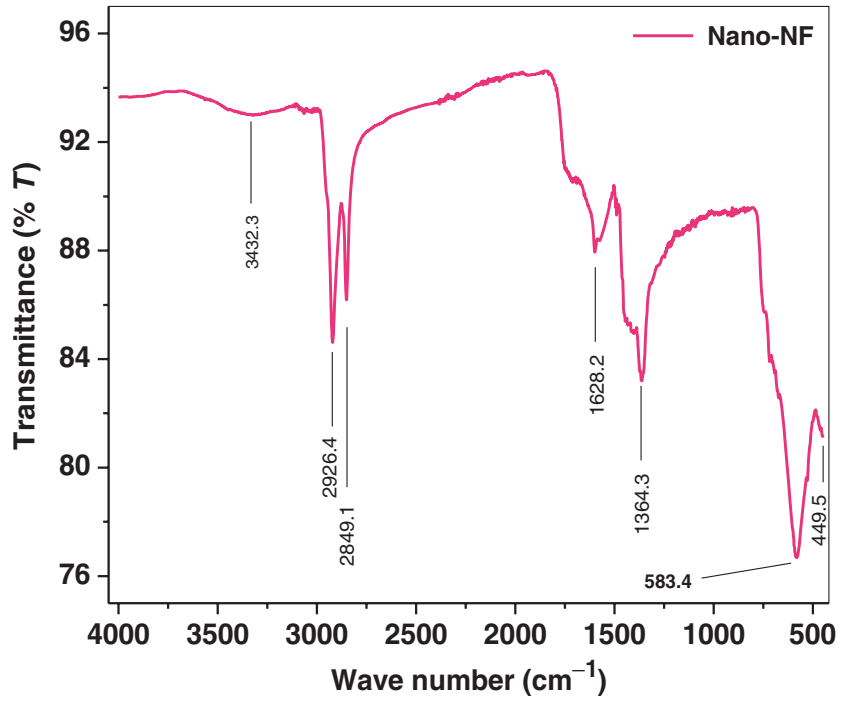

Figure 6. FT-IR spectra of $\mathrm{NiFe}_{2} \mathrm{O}_{4}$ nano-particles.

\section{$3.4 \quad$ FT-IR spectra}

FT-IR absorption spectrum in the range of $4000-400 \mathrm{~cm}^{-1}$ of as-prepared $\mathrm{NiFe}_{2} \mathrm{O}_{4}$ (NF) nano-particles is depicted in figure 6. Two kinds of metal-oxide (M-O) absorption bands are detected in the range of $400-590 \mathrm{~cm}^{-1}$, confirming the formation of spinel NF. Bands at wave numbers 449.5, 583.4, 1364.3, 1628.2, 2849.1, 2926.4 and $3432.3 \mathrm{~cm}^{-1}$ appeared in the FTIR spectrum of nano-ferrite sample. The first and second absorption bands around $449.5 \mathrm{~cm}^{-1}\left(v_{1}\right)$ and 583.4 $\mathrm{cm}^{-1}\left(\nu_{2}\right)[21,22]$ are associated with metal oxide $(\mathrm{Ni}-\mathrm{O}$ and $\mathrm{Fe}-\mathrm{O})$ stretching vibrations at octahedral $\mathrm{B}$-site and $\mathrm{Fe}-\mathrm{O}$ stretching vibrations at tetrahedral A-site, respectively [23]. The peak at $1364.3 \mathrm{~cm}^{-1}$ shows bending vibrations of $\mathrm{O}-$ $\mathrm{H}$ which are attributed to $\mathrm{OH}^{-}$absorbed by ferrites [22] Some absorption bands that occur at 2849.1 and $2926.4 \mathrm{~cm}^{-1}$ 

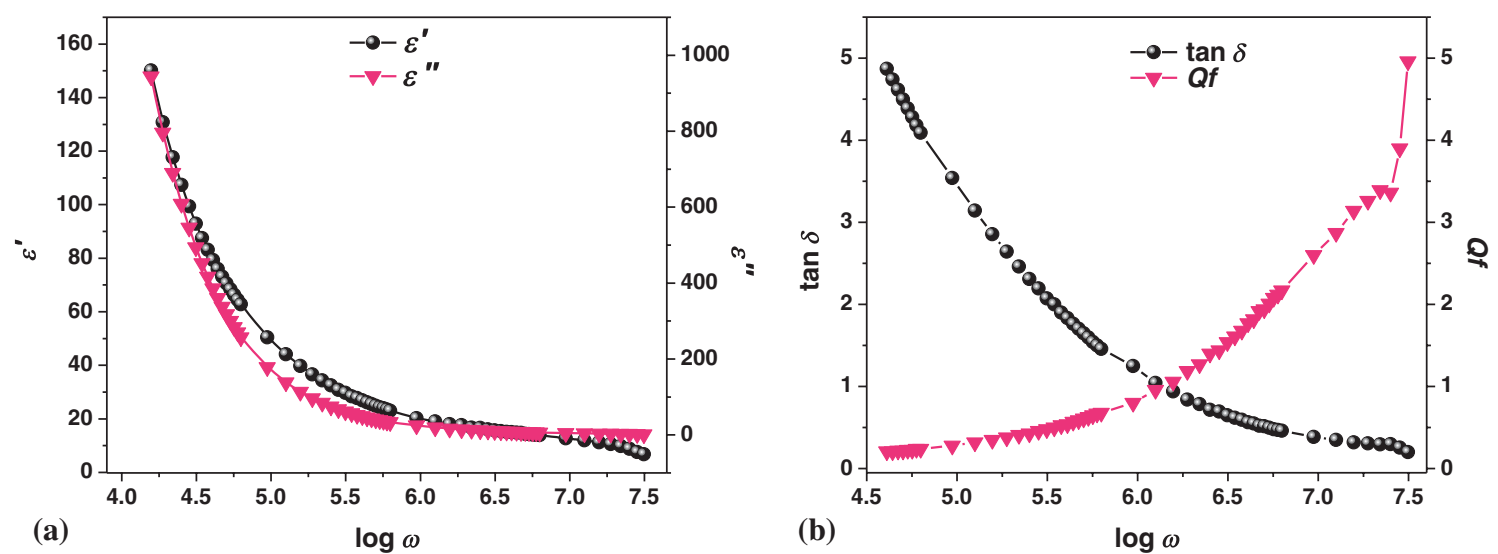

Figure 7. Variation of (a) real $\left(\varepsilon^{\prime}\right)$ and imaginary $\left(\varepsilon^{\prime \prime}\right)$ part of complex permittivity and (b) loss tangent $(\tan \delta)$ and quality factor $(Q f)$ with frequency.

are due to intra-molecular stretching modes that arise from different proportions of hydrogen bonding within the framework of tetrahedral bonded structure [24]. The detected bands at 1628.2 and $3432.3 \mathrm{~cm}^{-1}$ are due to $\mathrm{O}-\mathrm{H}$ stretching and bending vibrations of $\mathrm{H}_{2} \mathrm{O}$ molecules absorbed by nano-ferrites, respectively $[22,23]$. The force constants of both A-site $\left(K_{\mathrm{t}}=60.79 \mathrm{~N} \mathrm{~m}^{-1}\right)$ and B-site $\left(K_{\mathrm{o}}=25.15\right.$ $\mathrm{N} \mathrm{m}^{-1}$ ) are obtained by employing the Waldron method [25]. Mathematically, it is represented as

$$
\begin{aligned}
& K_{\mathrm{t}}=7.62 M_{\mathrm{t}} v_{\mathrm{t}}^{2} \times 10^{-7}\left(\mathrm{~N} \mathrm{~m}^{-1}\right), \\
& K_{\mathrm{o}}=5.31 M_{\mathrm{o}} v_{\mathrm{o}}^{2} \times 10^{-7}\left(\mathrm{~N} \mathrm{~m}^{-1}\right),
\end{aligned}
$$

where $M_{\mathrm{t}}$ and $M_{\mathrm{o}}$ are the molecular weights of cations at tetrahedral and octahedral sites, respectively.

\subsection{Electrical properties}

The frequency dependence of real and imaginary parts of complex permittivity $\left(\varepsilon^{*}=\varepsilon^{\prime}-\mathrm{j} \varepsilon^{\prime \prime}\right)$ is shown in figure $7 \mathrm{a}$. The $\varepsilon^{\prime}$ and $\varepsilon^{\prime \prime}$ are referred to as dielectric constant and dielectric loss, respectively. It can be seen from figure 7 a that $\varepsilon^{\prime}$ and $\varepsilon^{\prime \prime}$ achieve higher values at lower frequencies and decrease with increasing frequency. The Maxwell-Wagner interfacial polarization is responsible for high $\varepsilon^{\prime}$ and $\varepsilon^{\prime \prime}$ values at lower frequencies [26]. According to this theory, ferrimagnetic materials are assumed to have larger grains and smaller grain boundaries as conducting and insulating layers, respectively. Grain boundaries exhibit faster response to the input a.c. frequency at low frequencies, causing an increase in polarization. Hence, more number of ferrous $\left(\mathrm{Fe}^{2+}\right)$ ions are generated during the hopping mechanism, since hopping of carriers at the localized sites is universal in the Maxwell-Wagner double-layer model. Thus, $\varepsilon^{\prime}, \varepsilon^{\prime \prime}$ and $\tan \delta$ (dissipation factor) values increase as shown in figure $7 \mathrm{a}$ and $\mathrm{b}$. Moreover, grains are more active at high frequencies and lead to dielectric dispersion above certain critical frequencies. At these frequencies, the electron exchange oscillations between $\mathrm{Fe}^{3+}$
Table 2. Data on electrical and permeability studies of nano$\mathrm{NiFe}_{2} \mathrm{O}_{4}$.

\begin{tabular}{lc}
\hline Parameter & Value \\
\hline$\varepsilon^{\prime}(5 \mathrm{MHz})$ & 6.79 \\
$\varepsilon^{\prime \prime}(5 \mathrm{MHz})$ & 1.37 \\
$\tan \delta_{\mathrm{e}}(5 \mathrm{MHz})$ & 0.201 \\
$\sigma_{\text {a.c. }}\left(\mathrm{S} \mathrm{cm}^{-1}\right)$ & $3.82 \times 10^{-6}$ \\
$\left.\sigma_{\text {d.c. }}(\mathrm{S} \mathrm{cm})^{-1}\right)$ & $1.29 \times 10^{-6}$ \\
$\mu_{\mathrm{i}}(5 \mathrm{MHz})$ & 21.62 \\
$\mu^{\prime \prime}(5 \mathrm{MHz})$ & 0.209 \\
$\tan \delta_{\mathrm{M}}(5 \mathrm{MHz})$ & 0.0097 \\
$\tan \delta_{\mathrm{m}} / \mu_{\mathrm{i}}(5 \mathrm{MHz})$ & $4.49 \times 10^{-4}$ \\
$Q f(5 \mathrm{MHz})$ & 103 \\
\hline
\end{tabular}

and $\mathrm{Fe}^{2+}$ ions cannot follow the applied a.c. frequency. This lowers the values of dielectric parameters at higher frequencies. Quality factor $(Q f)$ is the reciprocal of loss tangent, and it increases with frequency. The slight knick observed in the loss tangent plot at higher frequencies must be due to the collective contribution of electrons and holes [27] at the interfacial boundary layer. In case of as-synthesized NF nanoparticles, low dielectric constant and low losses are obtained at high frequencies due to high specific surface area $(S)$ [28]. This high ' $S$ ' value is usually achieved owing to the small particle size (of $\mathrm{nm}$ range) of the sample. The values of a few dielectric parameters at $5 \mathrm{MHz}$ frequency are given in table 2 .

The frequency dependence of a.c. conductivity is shown in figure 8. It can be observed that the conductivity increases exponentially with increase of frequency up to $2.5 \mathrm{MHz}$. This happens due to sustained hopping of electrons between ferrous and ferric ions at octahedral sites [27]. After $4 \mathrm{MHz}$ frequency a sharp drop-off of conductivity is noticed. This may be due to unavailability of ferrous ions at octal position, i.e., hopping rate of electrons is decreased [27]. At $5 \mathrm{MHz}$ the achieved $\sigma_{\text {a.c. }}$ value is $3.82 \times 10^{-6} \mathrm{~S} \mathrm{~cm}^{-1}$, which is lower than the reported value $\left(1.7 \times 10^{-4}, \sim 8 \times 10^{-6}\right.$ and $\left.\sim 1.25 \times 10^{-5} \mathrm{~S} \mathrm{~cm}^{-1}\right)$ 
for NF nano-crystallites prepared by egg-white precursor, citrate-gel and co-precipitation method, respectively [27-29].

The d.c. conductivity is evaluated from a power-law fit to the plot as per the following equation:

$$
\sigma_{\text {a.c. }}(\omega, T)=\sigma_{\text {d.c. }}(T)+B \omega^{n}(\omega) \text {, }
$$

where $\sigma_{\text {d.c. }}$ is d.c. conductivity, $B$ is a constant, $n$ is the exponent and $\omega=2 \pi f$. In figure 8 the frequency-independent portion (between 2.5 and $4 \mathrm{MHz}$ ) is extrapolated towards $Y$-axis. Thus, the intersecting point establishes $\sigma_{\text {d.c. }}$ of $5.9 \times 10^{-6} \mathrm{~S} \mathrm{~cm}^{-1}$, whereas the exponent $(n)$ value equals 0.156 . The $n$ value is in good agreement with that reported by the sol-gel auto-combustion method [30].

\subsection{Impedance analysis}

Impedance spectroscopic studies are useful for investigating the electrical properties of ferrites and will give information about grains and grain boundaries. In accordance with the Maxwell-Wagner double-layer model, the grains are considered to be high-conductance layers while grain boundaries are treated as low-conductance layers. Figure 9 depicts the Cole-Cole plot ( $Z^{\prime}$ vs. $Z^{\prime \prime}$ ) of $\mathrm{NiFe}_{2} \mathrm{O}_{4}$ (NF) nano-particles at RT. The electron exchange between nickel and iron ions is responsible for the conduction mechanism in Nyquist plot. In this investigation the Cole-Cole plot shows two semicircular arcs within the complex plane. The first one is formed due to interfacial boundary (grain boundary) conduction at lower frequencies, while the latter is due the conduction through bulk crystals (grains) at high frequencies $[31,32]$. The centres of arcs lie below the real axis. Hence, it indicates the spread of relaxation with different (mean) time constants and confirms the non-Debye-type relaxation mechanism [32].

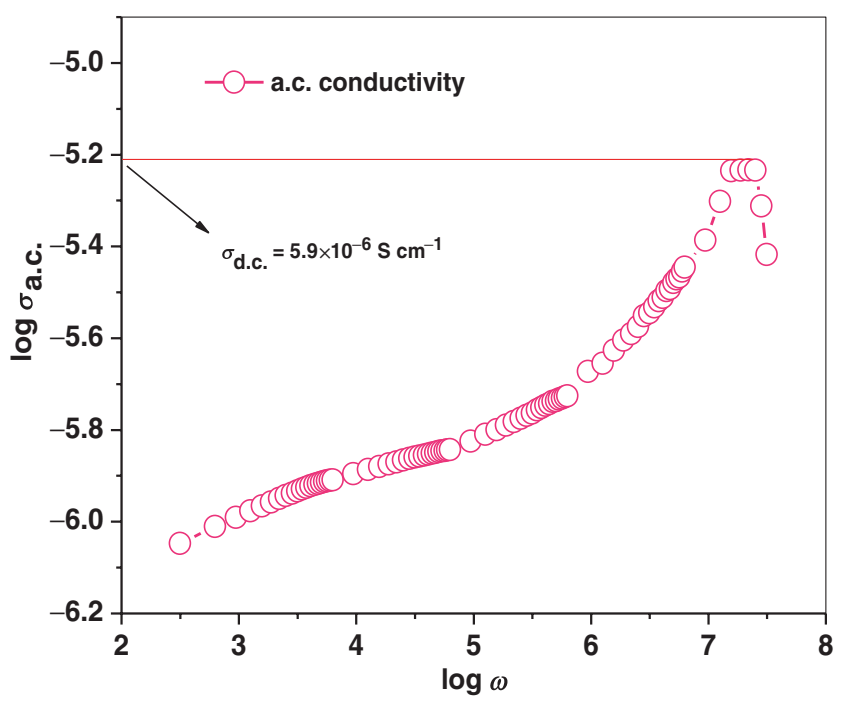

Figure 8. $\ln \sigma v$ s. frequency plot.
The obtained total bulk conductivity of NF is $\left(1.29 \times 10^{-6}\right.$ $\left.\mathrm{S} \mathrm{cm}^{-1}\right)$ in agreement with d.c. conductivity value $\left(3.82 \times 10^{-6}\right.$ $\mathrm{S} \mathrm{cm}^{-1}$ ) obtained from a.c. conductivity $v s$. frequency plot (figure 8 ). The values are higher than the reported value of $1.31 \times 10^{-8} \mathrm{~S} \mathrm{~cm}^{-1}$ at RT [33]. Therefore, this result also confirms the semi-conducting nature of the material. This happens owing to the contribution of conductivities of grains and grain boundaries. The impedance is generally evaluated by an equivalent circuit of two parallel RC-elements connected in series. With the help of Z-view software, RCelements are determined to be $R_{1}=0.13 \mathrm{M} \Omega, R_{2}=0.25$ $\mathrm{M} \Omega, C_{1}=5.09 \mathrm{pF}$ and $C_{2}=1.04 \mathrm{nF}$. The corresponding relaxation times $\left(\tau_{1}=R_{1} C_{1}\right.$ and $\left.\tau_{2}=R_{2} C_{2}\right)$ are evaluated. From the obtained results the relaxation time of grain $\left(\tau_{1}=\right.$ $0.65 \mu \mathrm{s})$ is smaller than its boundary value $\left(\tau_{2}=256.5 \mu \mathrm{s}\right)$ since the semicircle of grain stays at higher frequencies while the interfacial boundary lies at lower frequencies (i.e., $\tau=$ $1 / \omega)$.

The complex electric modulus $\left(M^{*}\right)$ is an indication of the extent of dielectric space-charge relaxation. The electric modulus is represented as $M^{*}=M^{\prime}+\mathrm{j} M^{\prime \prime}$ and can be calculated using the following relations:

$$
\begin{aligned}
& M^{\prime}=\frac{\varepsilon^{\prime}}{\varepsilon^{\prime 2}+\varepsilon^{\prime \prime 2}}, \\
& M^{\prime \prime}=\frac{\varepsilon^{\prime \prime}}{\varepsilon^{\prime 2}+\varepsilon^{\prime \prime 2}} .
\end{aligned}
$$

The RT electric modulus spectrum $\left(M^{\prime} v s . M^{\prime \prime}\right)$ is obtained from $50 \mathrm{~Hz}$ to $5 \mathrm{MHz}$ frequency. In figure 10, two prominent semicircular arcs are noticed and the centres of arcs lie below the real axis. Hence, it is confirmed that the non-Debye-type dielectric relaxation is assigned to the present NF [32].

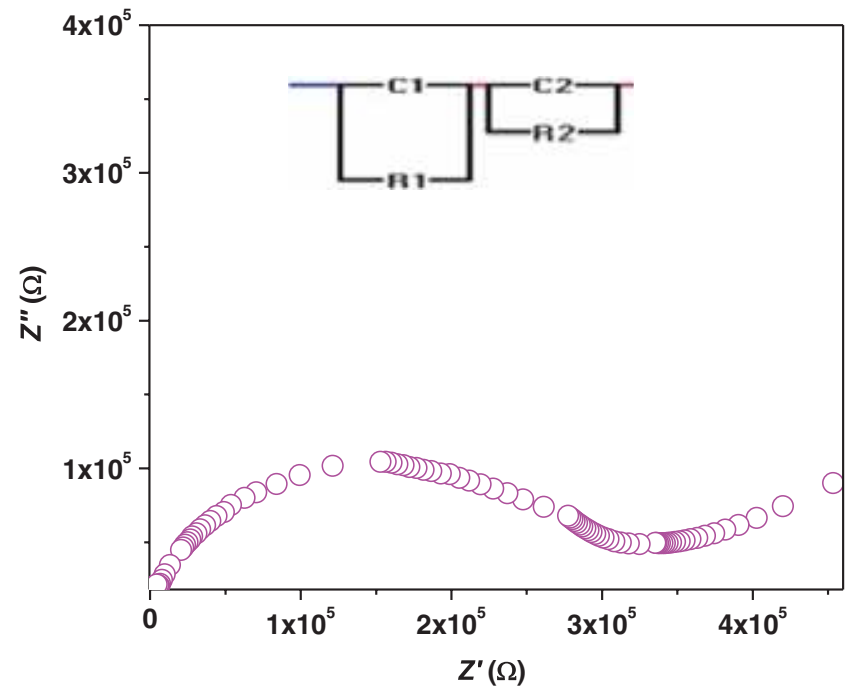

Figure 9. $Z^{\prime}$ vs. $Z^{\prime \prime}$ plot (Nyquist plot) of $\mathrm{NiFe}_{2} \mathrm{O}_{4}$ at room temperature. 


\subsection{Magnetic properties}

Figure 11 shows the frequency dependence of initial permeability $\left(\mu^{\prime}\right)$ and magnetic loss $\left(\mu^{\prime \prime}\right)$ of toroidal shaped nano-NF. These are calculated using the following relation:

$$
\begin{aligned}
\mu^{\prime} & =\frac{L_{\mathrm{s}}}{\left(0.004606 N^{2} h \log 10(D \mathrm{o} / D \mathrm{i})\right)}, \\
\mu^{\prime \prime} & =\mu^{\prime} \tan \delta,
\end{aligned}
$$

where $N$ is number of copper coil turns on the toroid (28 in this case), $h$ is thickness of the toroid (inches), $D_{\mathrm{o}}, D_{\mathrm{i}}$ are, respectively, outer and inner diameters (inches) and $L_{\mathrm{s}}$ is series inductance in $\mu \mathrm{H}$ [34]. It can be seen that the permeability increases with increase of frequency up to 0.4 $\mathrm{MHz}$. For further increase of frequency, $\mu^{\prime}$ decreases towards lower values due to resonance behaviour. As the applied field frequency matches with the precision frequency of dipoles, some amount of energy is propagated to the spinning dipoles

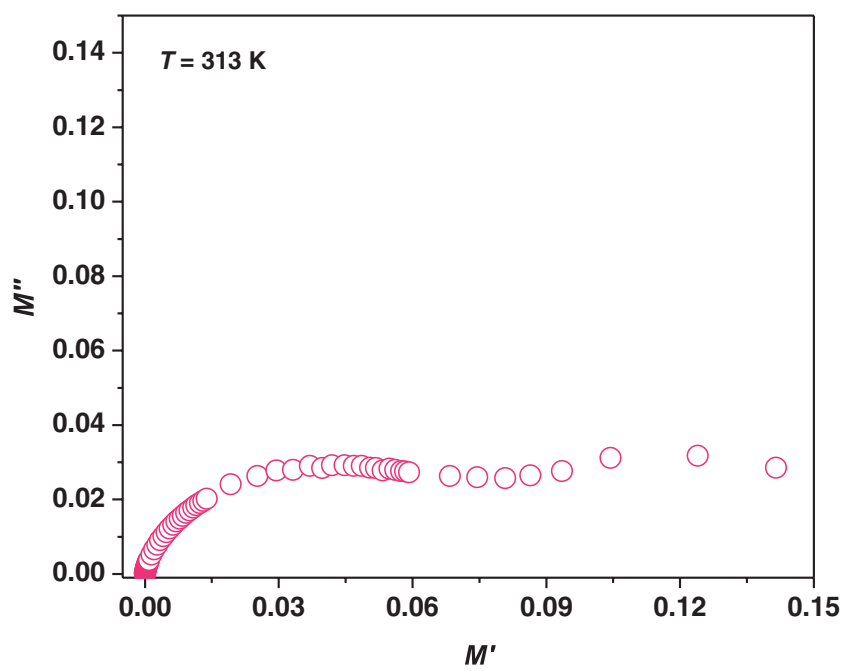

Figure 10. $M^{\prime}$ vs. $M^{\prime \prime}$ plot at RT.

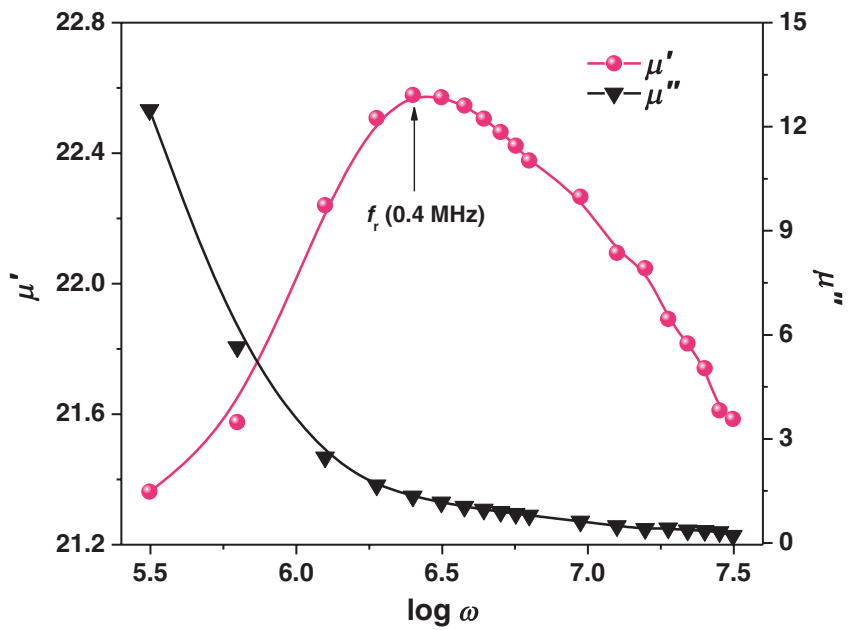

Figure 11. Frequency dependence of real $\left(\mu^{\prime}\right)$ and imaginary $\left(\mu^{\prime \prime}\right)$ part of permeability at RT. from input field. Therefore, $\mu^{\prime}$ reaches the maximum value at resonance frequency $\left(f_{\mathrm{r}}\right)$. Above $f_{\mathrm{r}}, \mu^{\prime}$ obeys Snoek's law as $f_{\mathrm{r}} \propto 1 /\left(\mu^{\prime}-1\right)$ [35]. The occurrence of ferromagnetic resonance peak is usual behaviour at higher frequencies [36]. On the other hand the magnetic loss $\left(\mu^{\prime \prime}\right)$ is generated due to the delay of magnetic dipoles in responding to the applied a.c. field frequency; $\mu^{\prime \prime}$ decreases with increase of frequency. Low magnetic loss of 0.209 is obtained for NF at $5 \mathrm{MHz}$. Generally permeability is a grain-size-dependent property. Bulk materials possess particle size of micron order containing smaller number of oxygen vacancies. However, in case of nano-materials the number of oxygen ion vacancies is much greater, resulting in high pinning effect [37]. This pinning effect reduces the domain wall motion, leading to the decrease of permeability when compared with their bulk counterpart. Relative loss factor $\left(\mathrm{rlf}=\tan \delta_{\mathrm{m}} / \mu^{\prime}\right)$

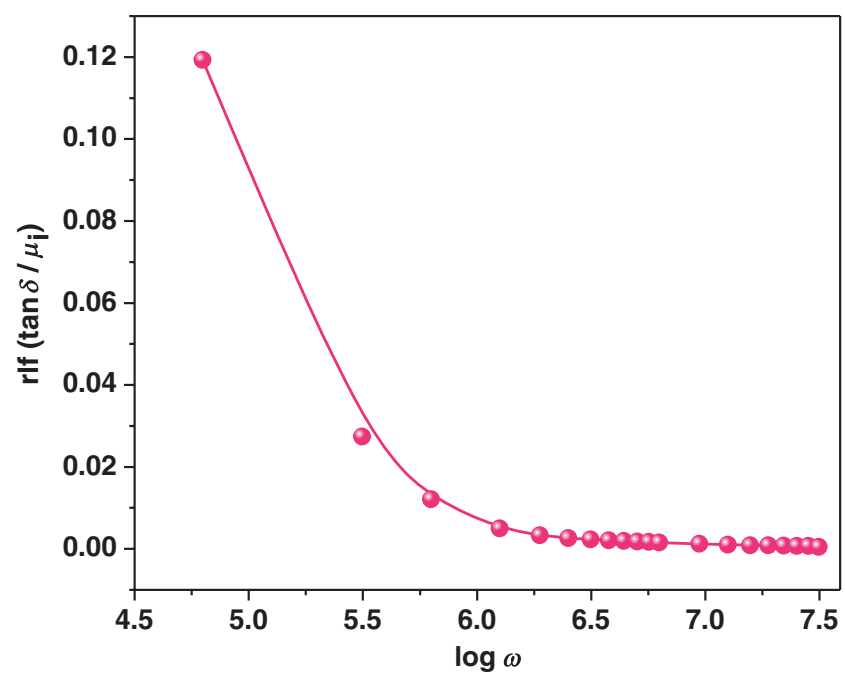

Figure 12. Frequency dependence of relative loss factor $\left(\tan \delta / \mu^{\prime}\right)$.

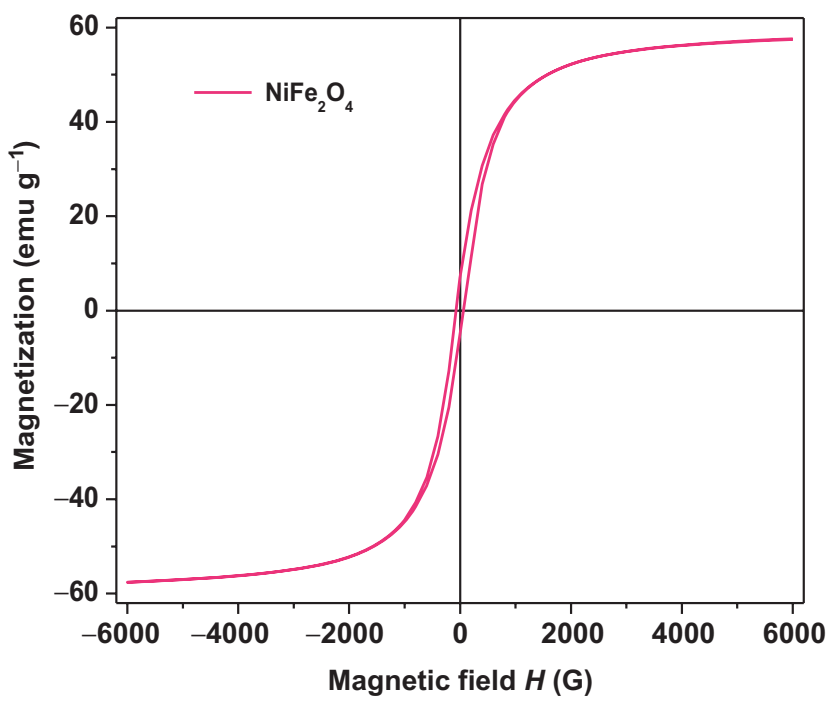

Figure 13. $M-H$ loop behaviour of $\mathrm{NiFe}_{2} \mathrm{O}_{4}$ nano-particles. 
is the ratio of magnetic loss tangent $\left(\tan \delta_{\mathrm{m}}\right)$ to permeability (figure 12). This must be as small as possible for device applications. In this study rlf decreases with increase of frequency and the lowest value achieved is of order $4.49 \times 10^{-4}$ at $5 \mathrm{MHz}$. Permeability-related parameters' data are listed in table 2.

Magnetic properties of ferrites such as magnetization $\left(M_{\mathrm{s}}\right)$, remanence $\left(M_{\mathrm{r}}\right)$, coercivity $\left(H_{\mathrm{c}}\right)$, anisotropic energy $\left(K_{1} \sim H_{\mathrm{c}} M_{\mathrm{s}} / 0.96\right)$, squareness $\left(M_{\mathrm{r}} / M_{\mathrm{s}}\right), M-H$ loop area $(A)$ and magnetic moment $\left(n_{\mathrm{B}}\right)$ are affected by cationic distribution in the sites, surface area and density. The $M-H$ loop (hysteresis loop) is traced for NF nano-particles at RT $(300 \mathrm{~K})$ and is shown in figure 13 . The corresponding magnetic parameters are reported in table 3 . As far as the cationic distribution of nano-NF is concerned, $\mathrm{Ni}^{2+}$ ions occupy $\mathrm{B}$ site as well as A-site [5]; hence a few $\mathrm{Fe}^{3+}$ ions migrate from B-site to A-site. If $M_{\mathrm{A}}$ and $M_{\mathrm{B}}$ are the magnetic moments of tetrahedral and octahedral sites, respectively, the net magnetic moment $\left(M=M_{\mathrm{B}}-M_{\mathrm{A}}\right)$ is equal to the experimental value of 2.417. Therefore the possible cationic distribution can be written as $\left[\mathrm{Ni}_{0.205} \mathrm{Fe}_{0.888}\right]_{\mathrm{A}}\left[\mathrm{Ni}_{0.795}\right]_{\mathrm{B}}\left[\mathrm{Fe}_{1.112}\right]_{\mathrm{B}} \mathrm{O}_{4}$. In this study nano-NF exhibited more $M_{\mathrm{s}}$ of $57.6 \mathrm{emu} \mathrm{g}^{-1}$ and $n_{\mathrm{B}}$ of $\left(2.417 \mu_{\mathrm{B}}\right)$ than the reported value using solvothermal technique [10] due to high specific surface area (low

Table 3. Data on $M-H$ loop parameters of nano- $\mathrm{NiFe}_{2} \mathrm{O}_{4}$.

\begin{tabular}{lccc}
\hline Parameter & Value & Literature & Reference \\
\hline$M_{\mathrm{S}}\left(\mathrm{emu} \mathrm{g}^{-1}\right)$ & 57.6 & 54.8 & 10 \\
$A\left(\mathrm{~cm}^{2}\right)$ & 1551.1 & - & - \\
$H_{\mathrm{c}}(\mathrm{G})$ & 65.1 & 59.4 & 10 \\
$M_{\mathrm{r}}\left(\mathrm{emu} \mathrm{g}^{-1}\right)$ & 0.714 & 9.8 & 2 \\
$M_{\mathrm{r}} / M_{\mathrm{s}}$ & 0.1024 & - & - \\
$K_{1}\left(\mathrm{erg} \mathrm{cm}^{-2}\right)$ & 21061.2 & - & - \\
$n_{\mathrm{B}}(\mu \mathrm{B})$ & 2.417 & - & - \\
$\left.\varepsilon_{\mathrm{p}}(\mathrm{erg} \mathrm{cm})^{-2}\right)$ & 0.244 & - & - \\
$D_{\mathrm{c}}(\mathrm{nm})$ & 15.4 & - & - \\
\hline
\end{tabular}

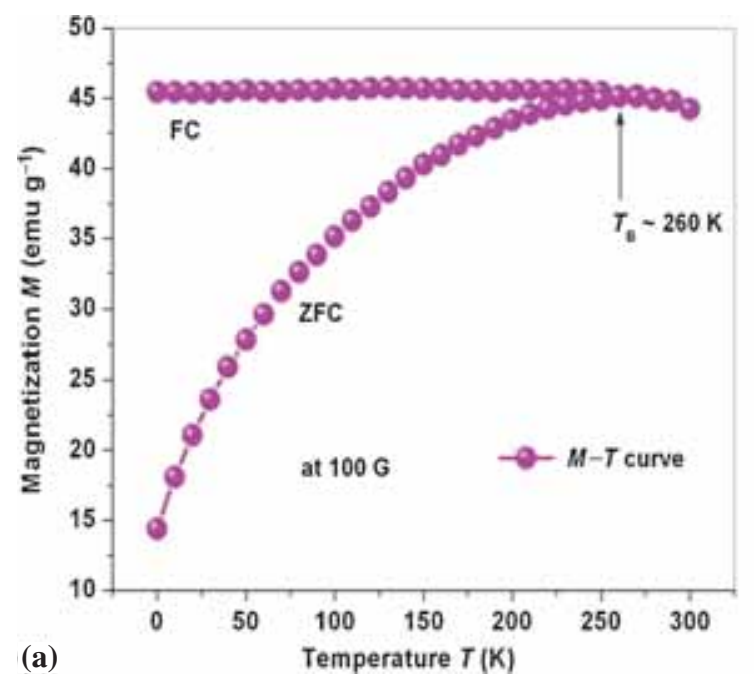

crystallite size) [1]. The critical diameter $\left(D_{\mathrm{c}}\right)$ is calculated from the following relation [38] and found to be $15.4 \mathrm{~nm}$ :

$$
D_{\mathrm{c}}=\frac{1.4 \varepsilon_{\mathrm{p}}}{M_{\mathrm{s}}^{2}}
$$

where $\varepsilon_{\mathrm{p}}=\left(2 K_{\mathrm{b}} T_{\mathrm{c}} K_{1} / a\right)^{1 / 2}$ is domain wall energy density, $M_{\mathrm{s}}$ is in Gauss, $K_{\mathrm{b}}$ is $1.38 \times 10^{-16} \mathrm{erg} \mathrm{K}^{-1}, T_{\mathrm{c}}(\mathrm{K})$ is the Curie temperature, $K_{1}$ is in erg cm${ }^{-3}$ and $a$ is lattice parameter $(\mathrm{cm})$ [39]. The obtained $D_{\mathrm{c}}(15.4 \mathrm{~nm})$ is of the order of crystallite diameter $(D)$ of $8.9 \mathrm{~nm}$. It is a well-known fact that if $D_{\mathrm{c}}>D$ the generated $H_{\mathrm{c}}$ is the contribution of domain wall displacement. Likewise, if $D_{\mathrm{c}} \sim D$, the coercivity is the result of domain-wall rotation [38]. Therefore, in this investigation the $H_{\mathrm{c}}, 65.1 \mathrm{G}$, is attributed to domain-wall rotation.

Figure 14a depicts the variation of magnetization as a function of temperature ( $M-T$ curve) of nano-NF. Zerofield-cooled (ZFC) magnetization measurements are carried out by cooling the NF in zero magnetic field and then the temperature is increased from 0 to $300 \mathrm{~K}$ under the applied field of $100 \mathrm{G}$. In the same way the field-cooled (FC) magnetizations are recorded by cooling NF from 300 to $0 \mathrm{~K}$ in $100 \mathrm{G}$ static field. The ZFC curve shows the maximum magnetization $\left(\sim 40 \mathrm{emu} \mathrm{g}^{-1}\right)$ at around $260 \mathrm{~K}$. This suggests the blocking of nano-particles at $260 \mathrm{~K}\left(T_{\mathrm{B}}\right)$ [40]. For the temperature greater than blocking temperature $\left(T>T_{\mathrm{B}}\right.$, i.e., $>260$ $\mathrm{K})$ the magnetic moment of single-domain particles is progressively unblocked and the magnetization in the presence of magnetic field attains its thermal equilibrium value, like an atomic paramagnet. However, since the magnetic moment of a single-domain particle is larger than that of an atom, the magnetic state for $T>T_{\mathrm{B}}$ is called super-paramagnetic, which exhibits almost zero values of coercivity and remanence of the material [41]. In this study, it happened at $T>260 \mathrm{~K}$. The super-paramagnetic nature of nano-NF particles is very much clear from the $M-H$ loop behaviour recorded at $270 \mathrm{~K}$, wherein the coercivity and remanence

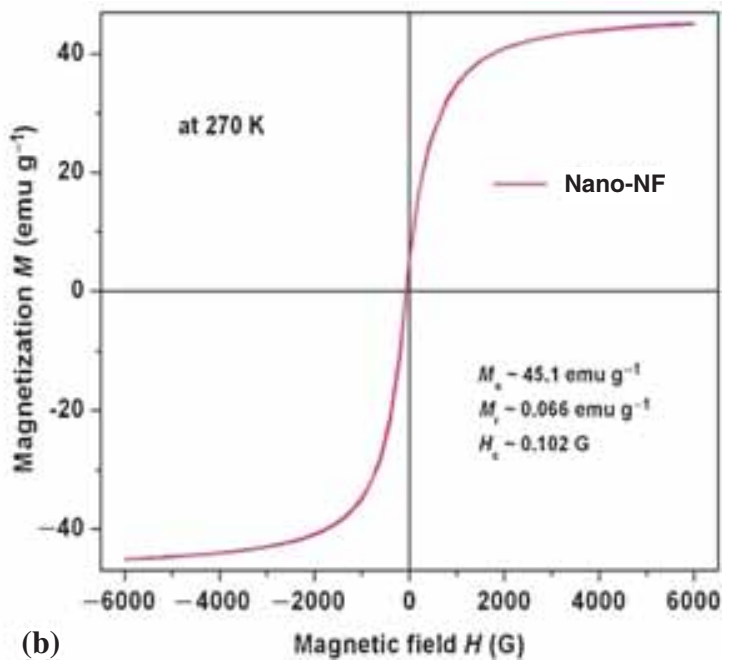

Figure 14. (a) $M-T$ curve and (b) $M-H$ loop (at $270 \mathrm{~K}$ ) behaviour of $\mathrm{NiFe}_{2} \mathrm{O}_{4}$ nano-particles. 
are almost equal to zero (figure 14b). At RT also the narrow $M-H$ loop with almost zero $M_{\mathrm{r}}$ and very small $H_{\mathrm{c}}$ values confirms the existence of super-paramagnetic nature.

\section{Conclusions}

Nickel ferrite nano-particles are prepared by hydrothermal technique. The obtained crystallite size is $8.9 \mathrm{~nm}$ with good crystallinity. The SAED confirms the formation of nano$\mathrm{NiFe}_{2} \mathrm{O}_{4}$ phases. Cole-Cole plots are drawn for complex impedance and dc-conductivity is found to be $1.29 \times 10^{-6}$ $\mathrm{S} \mathrm{cm}^{-1}$. The as-prepared samples show high saturation magnetization of $57.6 \mathrm{emu}^{-1}$ and coercivity of $65.1 \mathrm{G}$. The $M-T$ curve shows maximum magnetization $\sim 40 \mathrm{emu}^{-1}$ at blocking temperature $T_{\mathrm{B}} \sim 260 \mathrm{~K}$ and for $T>T_{\mathrm{B}}$ the NF shows super-paramagnetic nature. Low dielectric constant of 6.79 and low loss tangent of 0.201 are obtained at $5 \mathrm{MHz}$. The achieved low magnetic loss and low relative loss factor of $4.49 \times 10^{-4}$ at $5 \mathrm{MHz}$ are suitable for high-frequency magnetic applications.

\section{Acknowledgements}

This work is financially supported by DRDO Project, number ERIP/EP/1103015/M/01/1484/, dated 20.06.13, New Delhi. We also acknowledge SIF at SAS, VIT University, Vellore, and Dr S Manjunatha Rao from Central University Hyderabad for providing XRD, FTIR and VSM ( $M-T$ curve) facilities, respectively.

\section{References}

[1] Mahmoud M H, Elshahawy A M, Makhlouf S A and Hamdeh H H 2014 J. Magn. Magn. Mater. 36955

[2] Rafique M Y, Ellahi M, Iqbal M Z, Javed Q and Pan L 2016 Mater. Lett. 162269

[3] Gabal M A, Kosa S and Al Mutairi T S 2014 J. Mol. Struct. 1063269

[4] Ranjith Kumar E, Jayaprakash R and Kumar S J. Magn. Magn. Mater. 35170

[5] Atif M, Nadeem M and Siddique M 2015 Appl. Phys. A 120 571

[6] Luadthong C, Itthibenchapong V, Viriya-empikul N, Faungnawakij K, Pavasant P and Tanthapanichakoon W 2013 Mater. Chem. Phys. 143203

[7] Yehia M, Labib Sh and Ismail S M 2014 Physica B 44649

[8] Khairy M 2014 Synth. Met. 18934

[9] Marinca T F, Chicinas I, Isnard O, Pop V and Popa F 2011 J. Alloys Compd. $\mathbf{5 0 9} 7931$

[10] Zheng H, Ni Y, Xiang N, Ma X and Wan F 2015 Mater. Chem. Phys. 15882

[11] Gabal M A, El-Shishtawy R M and Al Angari Y M 2012 J. Magn. Magn. Mater. 3242258

[12] Gabal M A and Al Angari Y M 2009 Mater. Chem. Phys. 118153
[13] Moradmard H, Shayeshtech S F, Tohidi P, Abbas Z and Khalegi M 2015 J. Alloys Compd. 650116

[14] Zaki H M, Al-Heniti S H and Elmosalami T A 2015 J. Alloys Compd. 633104

[15] Wang J, Ren F, Yi R, Yan A, Qiu G and Liu X 2009 J. Alloys Compd. 479791

[16] Mahmoud M H, Elshahawy A M, Makhlouf S A and Hamdeh H H 2014 J. Magn. Magn. Mater. 36955

[17] Koferstein R, Walther T, Hesse D and Ebbinghaus S G 2013 J. Mater. Sci. 486509

[18] Chen W F, Chen H, Koshy P and Sorrell C C 2015 J. Aust. Ceram. Soc. $\mathbf{5 1} 1$

[19] Dixit G, Singh J P, Srivastava R C, Agrawal H M and Chaudhary R J 2012 Adv. Mater. Lett. 321

[20] Donnerberg H and Birkholz A 2000 J. Condens. Matter Phys. 128239

[21] Moradmard H, Shayeshtech S F, Tohidi P, Abbas Z and Khalegi M 2015 J. Alloys Compd. 650116

[22] Dumitrescu A M, Lisa G, Iordan A R, Tudorache F, Petrila I, Borhan A I, Palamaru M N, Mihailescu C, Leontie L and Munteanu C 2015 Mater. Chem. Phys. 156170

[23] Sattara A A, El-Sayeda H M and Alsuqia I 2015 J. Magn. Magn. Mater. 39589

[24] Singh J P, Dixit G, Srivastava R C, Agrawal H M and Kumar R 2013 J. Alloys Compd. $\mathbf{5 5 1} 370$

[25] Gabal M A, El-Shishtawy R M and Al Angari Y M 2012 J. Magn. Magn. Mater. 3242258

[26] Wagner K 1913 Ann. Phys. 40817

[27] Berchmens L J, Selvan R K, Kumar P N S and Augustin C O 2004 J. Magn. Magn. Mater. 279103

[28] Gabal M A, Al Angari Y M and Zaki H M 2014 J. Magn. Magn. Mater. 3636

[29] Varshney D and Verma K 2013 Mater. Chem. Phys. 140412

[30] Mocanu Z V, Airimioaei M, Ciomaga C E, Curecheriu L, Tudorache F, Tascu S et al 2014 J. Mater. Sci. 493276

[31] Dzunuzovic A S, Ilic N I, Vijatovic Petrovic M M, Bobic J D, Stojadinovic B, Dohcevic-Mitrovic Z and Stojanovic B D 2015 J. Magn. Magn. Mater. 374245

[32] Ranjan R, Kumar N, Behera B and Choudhary R N P 2014 Adv. Mater. Lett. 5138

[33] Senthilkumar B, Kalai Selvan R, Vinothbabu P, Perelshtein I and Gedanken A 2011 Mater. Chem. Phys. 130285

[34] Ghodake J S, Shinde T J, Patil R P, Patil S B and Suryavanshi S S 2015 J. Magn. Magn. Mater. 378436

[35] Roy P K and Bera J 2012 Mater. Chem. Phys. 132354

[36] Stergiou C A and Litsardakis G 2016 J. Magn. Magn. Mater. 40554

[37] Song S, Song Q, Li J, Ramana M V and Zhang Z 2014 Ceram. Int. 406473

[38] Caizer C 2015 Handbook of nanoparticles (Switzerland: Springer International Publishing) doi:10.1007/978-3-31913188-7-24-1

[39] Caizer C and Stefanescu M 2003 Physica B 327129

[40] Dolia S N, Subhash Chander, Sharma M P and Sudhish Kumar 2006 Indian J. Pure Appl. Phys. 44169

[41] Atif M, Nadeem M and Siddique M 2015 Appl. Phys. A 120571 